\title{
Turismo e a dinâmica sócioespacial do litoral de Santa Catarina
}

\author{
Tourism and the sociospatial dynamics of the coast of the state of Santa \\ Catarina
}

El turismo y la dinámica socioespacial del litoral de Santa Catarina

\author{
Raquel Maria Fontes do Amaral Pereira ${ }^{1}$
}

\begin{abstract}
Resumo: O artigo analisa as mudanças na dinâmica sócioespacial do litoral de Santa Catarina nas últimas décadas, relacionando dialeticamente elementos naturais e humanos e considerando as determinações locais, regionais, nacionais e mundiais responsáveis por sua configuração atual, marcada pela intensa movimentação de veículos nas rodovias federais e estaduais, em razão do desenvolvimento do turismo e do permanente tráfego de cargas e pessoas. 0 método de abordagem apoia-se no materialismo histórico-dialético, recorrendo fundamentalmente ao paradigma de formação socioespacial que favorece a identificação das "múltiplas determinações" responsáveis pela caracterização de realidades concretas. A investigação demonstrou o dinamismo sócio- espacial do litoral catarinense, resultado uma intensa movimentação de pessoas e de mercadorias.
\end{abstract}

Palavras-chave: Turismo. Dinâmica sócioespacial. Litoral de Santa Catarina.

\begin{abstract}
The article analyzes the changes in the sociospatial dynamics of the coast of the State of Santa Catarina within the last decades, dialectically connecting natural and human elements and considering the local, regional, national and international determinations that are responsible for its current configuration, characterized by the intense traffic on the federal and state freeways, due to the tourism development and permanent traffic loads and people. The approach method is supported by dialectical and historical materialism, essentially resorting to the socio-spatial paradigm, which favors the identification of the "multiple determinations" responsible for the characterization of concrete realities. Research has shown the dynamism of sociospatial Santa Catarina coast, resulting in an intense movement of people and goods.
\end{abstract}

Keywords: Tourism. Sociospatial dynamics. Coast of the State of Santa Catarina.

Resumen: El articulo analiza los cambios en la dinámica socioespacial del litoral de Santa Catarina en las últimas décadas, relacionando dialecticamente elementos naturales y humanos y considerando las determinações locales, regionales, nacionales y mundiales responsables por su configuración actual, marcada por el intenso movimiento de vehículos en las carreteras nacionales y provinciales, en razón del desenvolvimiento del turismo y del permanente tráfego de cargas y de personas. El método de abordaje se apoya en el materialismo histórico dialéctico, recurriendo fundamentalmente al paradigma de formación socioespacial que favorece la identificación de las "múltiples determinaciones" responsables por la caracterización de realidades concreta., La investigación ha demostrado el dinamismo socioespacial de la costa de Santa Catarina, lo que resulta en un intenso movimiento de personas y bienes.

Palabras clave: Turismo. Dinámica sócioespacial. Litoral de Santa Catarina.

1 Universidade do Vale do Itajaí- UNIVALI. Email: raquel.fontes@univali.br 


\section{INTRODUÇÃO}

Nos dias de hoje, é inegável a relevância do litoral do estado de Santa Catarina, tanto no que se refere ao grande dinamismo demográfico e socioeconômico dos municípios nele localizados quanto no que diz respeito à movimentação de turistas nacionais e estrangeiros, somados à formação de um circuito espacial singular, responsáveis por uma intensa movimentação de pessoas e de mercadorias.

O adensamento da população brasileira na faixa litorânea tem, como se sabe, raízes históricas decorrentes do processo de colonização pelos portugueses. Santa Catarina, porém, dentre os estados que formam a região sul, é o único que, desde o início do processo de colonização, concentra o maior contingente populacional na faixa costeira onde foram surgindo os primeiros povoados ao longo da costa. As características do seu quadro natural e a evolução do processo histórico de ocupação do território, reforçadas pela facilidade dos contatos por via marítima, além do predomínio da pequena produção mercantil, explicam a concentração de núcleos urbanos no litoral catarinense.

Para se ter uma ideia da vitalidade dessa região, basta lembrar que a rede urbana litorânea de Santa Catarina, concentrava em 2010, de acordo com o IBGE, dez dos doze municípios mais populosos do estado (com população entre 500.000 e 100.000 habitantes), assim colocados, segundo a magnitude de sua população: 1) Joinville; 2) Florianópolis; 3) Blumenau; 4) São José; 5) Criciúma; 6) Chapecó; 7) Itajaí; 8) Lages; 9) Jaraguá do Sul; 10) Palhoça; 11) Balneário Camboriú e 12) Brusque. Dentre eles, apenas os municípios de Chapecó e Lages não estão localizados na denominada região do "Litoral e encostas". Essa realidade que se acentuou, sobretudo no decorrer das três últimas décadas, permite falar em uma reestruturação sócioespacial da fachada atlântica catarinense, por conta do seu acelerado dinamismo frente ao contexto geoeconômico estadual e sul-brasileiro, reestruturação essa que pode ser definida como uma fase entre o "velho" e o "novo", na qual as práticas sociais preexistentes e as novas disputam entre si o controle/comando das forças definidoras da vida material das sociedades.

O texto parte da constatação de que as transformações sócioespaciais que vem ocorrendo na região do "Litoral e encostas" (Peluso, 1991) resultam da busca do capitalismo por novos arranjos capazes de assegurar a sua reprodução e sobrevivência, fato esse que repercute de forma diferenciada sobre os lugares. Isso significa dizer que os espaços não podem ser estudados como se os objetos neles contidos guardassem em si mesmos sua própria explicação, o que exige a consideração dos processos geradores das formas, o que leva ao reconhecimento das noções de tempo e espaço, já que a produção espacial resulta de múltiplas determinações, cujas origens se situam em níveis diferentes e em escalas variáveis, indo do simples lugar à dimensão internacional (PEREIRA, 2015, p.511).

Diante desse cenário, o presente artigo tem como objetivo geral analisar as mudanças na dinâmica sócioespacial do litoral de Santa Catarina nas últimas décadas, relacionando dialeticamente elementos naturais e humanos e considerando as determinações locais, regionais, nacionais e mundiais responsáveis por sua configuração atual, marcada pela intensa movimentação de veículos nas rodovias federais e estaduais, em razão do desenvolvimento do turismo e do permanente tráfego de cargas e pessoas.

Sua matriz teórica está assentada no materialismo histórico e dialético, apoiando-se fundamentalmente no paradigma de formação sócioespacial (Santos, 1982) que, ao acrescentar a categoria espaço ao 
conceito de formação econômico-social, permite considerar as combinações geográficas (Cholley, 1964) responsáveis por realidades concretas, cujas particularidades são definidas espacial e temporalmente. Tal perspectiva ao mesmo tempo em que abre novas e importantes possibilidades para estudos na área da Geografia, aproximando-a da abordagem marxista focada nas "múltiplas determinações" naturais e humanas que, ao longo do tempo e em diferentes escalas, moldam as formações sócioespaciais. A linha interpretativa é reforçada também pela teoria dos ciclos econômicos aplicada à evolução da formação social brasileira (Rangel, 2005), cuja periodização, definida por rupturas e continuidades na estrutura econômica e política, é marcada pela formação de novos pactos de poder que dão origem às dualidades básicas (Rangel, 2005).

$\mathrm{Na}$ análise da especificidade catarinense adotou-se a perspectiva teórica defendida por A. Mamigonian (1966 e 1986), que destaca o papel da pequena produção mercantil no desenvolvimento sócioeconômico das áreas de colonização européia do Sul, bem como no processo de acumulação ocorrido no Sudeste do Brasil.

A investigação, além de exigir uma revisão bibliográfica e a busca de informações geohistóricas, tem um caráter exploratório, imprescindível ao levantamento de dados empíricos. Como fontes secundárias, foram utilizadas buscas na internet, pesquisa documental, bem como estudos comparativos com base em mapas e dados estatísticos.

\section{SINGULARIDADES DA FORMAÇÃO ECONÔMICA LITORÂNEA CATARINENSE}

As transformações em curso na fachada atlântica de Santa Catarina ocorrem sobre uma base material pré-existente que M. Santos denomina de "rugosidades", definidas como aquilo que "fica do passado como forma, espaço construído, paisagem, o que resta do processo de supressão, acumulação, superposição, com que as coisas se substituem e acumulam em todos os lugares" (1997, p. 113). Por essa razão, ao analisar a nova dinâmica sócioespacial vigente, faz-se necessário levar em conta as origens dessa formação num esforço para identificar em que medida as heranças do passado facilitam ou inibem as mudanças, bem como levantar os elementos capazes de explicar rupturas e continuidades registradas ao longo desse processo, tendo o cuidado de interpretá-lo inserido em um contexto mais amplo, qual seja, o da evolução das forças produtivas e suas repercussões locais. Assim, pois, para se compreender a configuração sócioespacial da faixa litorânea catarinense e sua relevância no contexto estadual e nacional, é necessário levantar as conexões básicas entre o passado e o presente, identificando marcos históricos mais significativos de sua trajetória, iniciada com a ocupação vicentista e consolidada pelos açorianos que representaram a primeira corrente imigratória pequeno produtora a se estabelecer nessa área, num período ainda dominado pelo mercantilismo (Pereira, 2011). A abordagem do tema exige, igualmente, o estabelecimento de relações entre as características naturais e humanas próprias da área foco desse artigo e as determinações extrínsecas que atuam ou atuaram sobre essa formação sócioespacial, cuja dinâmica resulta de um conjunto de fatores socioeconômicos e políticos que promoveram reestruturações em diversas esferas, refazendo as formas espaciais para atender as exigências de um novo estágio do desenvolvimento do capitalismo. Por outro lado, o presente estudo depois de salientar o cenário dominante no estado de Santa Catarina no final do século XIX e início do século XX, volta-se para o período compreendido entre 1950 e os dias atuais, 
subdividido em três momentos distintos: o primeiro situado entre as décadas de 50 e 60 do século passado, marcado já por uma lenta recuperação da decadência da antiga formação sócioespacial das áreas litorâneas de colonização açoriana e pela vitalidade das áreas industriais de colonização européia; o segundo entre as décadas de 1970 e 1990, afetado por mudanças impulsionadas por forte intervenção do Estado na economia brasileira e o terceiro, situado entre o final da década de 1990 e os dias atuais.

A crise do modelo implantado nas áreas de colonização açoriana, iniciada no século XIX, se aprofundou no início do século XX, pois em Santa Catarina, tal como no restante do Brasil, a terceira dualidade, conforme Rangel (2005), esvaziou o poder dos comerciantes de importação e exportação que controlavam os negócios nas praças comerciais litorâneas. Em Florianópolis, contudo, comerciantes de origem alemã, substitutos dos açorianos desde o final do século XIX, permaneceram vinculados aos capitais comerciais tradicionais do Rio de Janeiro pela navegação de cabotagem, o que retardou a implantação das mudanças impostas pelo estabelecimento das relações capitalistas de produção, prolongando a estagnação econômica da capital catarinense e das áreas litorâneas. Esses comerciantes exerceram um papel importante "nas decisões locais e estaduais, tendo aplicado parte significativa do excedente econômico na modernização do comércio e do porto, ampliando as relações comerciais, sobretudo através da navegação de cabotagem" (Pereira, 2003, p. 113). No período marcado pela Revolução de 1930, teve início no país um novo pacto político que uniu os latifundiários feudais ligados ao mercado interno e a burguesia industrial nascente, camadas sociais nacionalistas que imprimiram um novo rumo ao desenvolvimento brasileiro.

A conjuntura política e econômica implantada a partir da Revolução de 1930 acelerou o processo de industrialização e de integração do território brasileiro através da implantação de um sistema rodoviário nacional, consolidando o desenvolvimento industrial e comercial das áreas de colonização européia que passaram a produzir para regiões cada vez mais distantes, as quais se ligavam agora por via terrestre. Os estabelecimentos industriais iniciados modestamente pelos imigrantes nos núcleos coloniais situados em território catarinense souberam aproveitar a queda das barreiras regionais, ao mesmo tempo em que o declínio das importações causado pela crise depressiva do capitalismo (1921-1948), permitiu a ampliação do mercado consumidor. $O$ espírito empreendedor originário do ambiente de extrema concorrência inerente às áreas em que dominava o pequeno modo de produzir, marcado por disputas entre as múltiplas iniciativas, imprimiu uma pujança econômica às áreas de colonização dos vales atlânticos que acabou extravasando para a faixa litorânea, numa evidente demonstração da vitalidade da pequena produção mercantil desses núcleos coloniais. Esse é o caso, por exemplo, do Balneário Camboriú, o mais famoso balneário do litoral de Santa Catarina, cuja origem e crescimento não se explicam sem a influência das colônias alemães do Vale do Itajaí cuja expansão, na primeira metade do século XX, até a faixa costeira do então município de Camboriú, do qual se emanciparia em 1964, trouxe consigo o empreendedorismo intrínseco dos descendentes de imigrantes do vale do rio Itajaí-Açú. No litoral onde predominava a população descendente de açorianos, o 
desenvolvimento das relações capitalistas de produção, apesar da estrutura agrária baseada na pequena propriedade assegurar a sobrevivência de pequenos produtores independentes e permitir a comercialização dos excedentes, foi bloqueado por um complexo de fatores, diferentemente do que ocorria nos núcleos coloniais fundados a partir de meados do século XIX, onde a pequena produção mercantil - a via revolucionária para o capitalismo - foi responsável pela precoce e acelerada industrialização de Santa Catarina (Mamigonian, 2000). Apesar da origem modesta, essas indústrias foram favorecidas pela conjuntura depressiva do comércio internacional de 1873 a 1896 (fase recessiva do segundo ciclo longo), mantendo vínculos com a Europa (Alemanha) no que se refere à atualização das técnicas de trabalho e do maquinário para a produção, além de contar ainda com apoio de lideranças políticas originárias desses núcleos de imigrantes no âmbito estadual e nacional. O crescimento industrial catarinense se fez de forma lenta e segura alcançando o mercado do Sul do Brasil e até mesmo do Rio de Janeiro e São Paulo ainda antes da I Guerra Mundial (1914-1919).

\section{CONCENTRAÇÃO GEOGRÁFICA E DINAMISMO SOCIOECONÔMICO NO LITORAL CATARINENSE}

A partir das décadas de 1950 e 1960, os núcleos litorâneos que haviam alcançado posição de destaque como áreas fornecedoras de gêneros alimentícios movimentando várias praças comerciais, entre as quais se destacavam São Francisco, Itajaí, Desterro e Laguna começaram a emergir do processo de esvaziamento e marginalização provocados pela decadência da pequena produção mercantil açoriana, no qual permaneceram mergulhados por quase toda a primeira metade do século XX. Esse quadro passa a ser modificado por uma nova conjuntura promotora de grandes transformações que foram, gradativamente, inserindo essas áreas no contexto do capitalismo industrial brasileiro e catarinense, com uma forte participação do Estado como fomentador do desenvolvimento econômico do país, sobretudo nos anos de 1930 a 1970. Desde o período Vargas (1930-1945) ${ }^{2}$, os diferentes governos fixaram políticas estratégicas para o desenvolvimento econômico e social brasileiro ${ }^{3}$, as quais colocadas em prática no âmbito federal repercutiram nos diversos estados da federação que buscavam alternativas para o processo de desenvolvimento através do estímulo às atividades produtivas, com consequências na economia e também na organização espacial.

O processo de dinamização socioeconômica das localidades costeiras de Santa Catarina foi estimulado, como já foi destacado, pelo deslocamento para essas áreas de um grande número de descenden-

2 Com o final da "República Velha", encerrada com a Revolução de 1930, a ditadura Vargas que se estendeu de 1930 a 1945, adotou um modelo econômico para o país que privilegiava o mercado interno, em substituição ao modelo anterior apoiado na agroexportação do café, principal produto escoado pelo porto de Santos.

3 O governo de Juscelino Kubitschek (1956-1961), através do Plano de Metas, privilegiou a solução de problemas setoriais, promovendo a expansão da economia nacional e a abertura ao capital estrangeiro para instalação de indústrias no país, com destaque para bens de consumo duráveis, em especial a indústria automobilística. Já no período da ditadura militar, o Governo Federal lançou o I e o II PND (Plano Nacional de Desenvolvimento) que visavam a uma maior integração nacional e uma desconcentração industrial, expressa na construção de grandes pólos industriais, entre os quais a Zona Franca de Manaus (AM) e o Pólo Petroquímico de Camaçari (BA). 
tes de imigrantes oriundos dos vales de colonização européia que nelas deram início a vários empreendimentos ligados à prestação de serviços para atender famílias de veranistas que, a partir das primeiras décadas do século XX, introduziram o costume de veranear. No pós-II Guerra Mundial o veraneio difundiu-se rapidamente, a ponto de, por exemplo, em 1952, o pedido de construções encaminhado à prefeitura de Camboriú (o município de Balneário Camboriú seria criado em 1964) saltar, conforme dados publicados pelo Arquivo Histórico de Balneário Camboriú (2009), de 58 para 620 casas.

$\mathrm{Na}$ década de 1970, as melhorias na acessibilidade influenciaram decisivamente na expansão da prática do turismo de veraneio (dezembro, janeiro e fevereiro), processo que se intensificou com o deslocamento de fluxos de turistas nacionais e estrangeiros, especialmente argentinos, atraindo novas iniciativas de ocupação e exploração da orla marítima catarinense marcada por sua atratividade natural. A integração do território nacional que vinha se desenrolando desde a década de 1960 ganhou maior impulso nos anos de 1970. A construção da BR-101, iniciada em 1953 e concluída em 1971, "aproxima o litoral catarinense dos estados vizinhos, propiciando a chegada de turistas procedentes destes estados, bem como de outros situados no centro-sul do país e até mesmo da Argentina e do Uruguai" (Pereira, 2013). Além da contribuição da malha rodoviária ${ }^{4}$ para a integração regional, a abertura da BR-101 representou um grande impulso para o litoral catarinense tornando-o alvo de grandes investimentos direcionados para o setor imobiliário e da construção civil, que passaram a atrair trabalhadores de outras regiões do estado e do país, bem como investidores de diferentes origens. Sobretudo na alta temporada, quando os fluxos de turistas nacionais e estrangeiros aumentam ainda mais o movimento na orla catarinense, é visível o crescimento da quantidade de veículos que trafegam pelas principais rodovias estaduais e federais da faixa litorânea do estado, como pode ser constatado na tabela 1 que apresenta a movimentação média diária de veículos na praça de pedágio da BR-101 em Porto Belo, município litorâneo catarinense.

A intensa movimentação de veículos nas rodovias federais e estaduais que cortam a faixa costeira do estado pode ser explicada pelo permanente fluxo de cargas transportadas por via rodoviária no sentido sul-norte, como também em razão do elevado aumento da frota de veículos de Santa Catarina que cresceu 153,56\% no período de 2001 a 2013, representando um incremento de 2.531.879 veículos. Cabe destacar que na alta temporada é intenso o fluxo de turistas nacionais e estrangeiros que chegam aos vários balneários da orla catarinense, entre os quais se destacam Balneário Camboriú, Itapema, Bombinhas, Balneário Piçarras e a própria capital do estado que com suas numerosas praias atraem turistas nacionais e estrangeiros.

4 A emergência da era rodoviária, a partir dos anos de 1950, relegou a um plano secundário o transporte ferroviário, marcado por uma rigidez e linearidade responsáveis por certa inércia espacial decorrente da implantação de fixos de elevados custos. A substituição do sistema ferroviário por um meio de transporte de natureza flexível favoreceu o acesso quase irrestrito às diferentes localidades, provocando um forte impacto na redefinição dos espaços. Aliada ao sistema rodoviário federal que facilitava o contato direto com as duas metrópoles da Região Sul e com o restante do país, a rede de rodovias estaduais exerceu um papel decisivo na configuração urbana de Santa Catarina. 
Tabela 1- Número Diário de Veículos na Praça de Pedágio da BR101, em Porto Belo/SC

\begin{tabular}{ll}
\hline Mês & NDV \\
\hline Janeiro/2013 & 50.070 \\
Fevereiro/2013 & 45.135 \\
Março/2013 & 41.651 \\
Abril/2013 & 40.087 \\
Maio/2013 & 39.199 \\
Junho/2013 & 38.140 \\
Julho/2013 & 40.323 \\
Agosto/2013 & 39.717 \\
Setembro/2013 & 40.219 \\
Outubro/2013 & 42.475 \\
Novembro/2013 & 44.678 \\
Dezembro/2013 & 48.299 \\
Janeiro/2014 & 51.744 \\
Fevereiro/2014 & 47.356 \\
Março/2014 & 44.773 \\
\hline
\end{tabular}

Fonte: Ouvidoria da ALS (Autopista Litoral Sul)

Santa Catarina é o estado que, de acordo com pesquisa realizada pelo Instituto Brasileiro de Planejamento Tributário (IBPT, 2011), tem mais veículos por habitante. O índice é de 1,61 veículos por habitante. Em segundo lugar na pesquisa aparece o Paraná, com 0,56, e em terceiro, São Paulo, com 0,55. Ainda segundo dados da frota de veículos do DENATRAN e do censo de 2010 do Instituto Brasileiro de Geografia e Estatística (IBGE, 2010), 10 municípios catarinenses encontram-se entre os 50 com maior proporção de veículos por habitante no Brasil, conforme demonstra a tabela 2. Entre eles, apenas Chapecó não está situado na fachada atlântica, fato que demonstra a pujança da formação regional litorânea em que predomina a pequena produção mercantil. Os demais municípios localizam-se na denominada região do "litoral e encostas", muito embora alguns deles, como é o caso de Brusque, Blumenau, Jaraguá do Sul e Criciúma, não sejam litorâneos. Cabe, finalmente, destacar que Brusque e Blumenau estão entre os 10 municípios brasileiros com a maior proporção de veículos por habitante.

Aliada ao sistema rodoviário federal que facilitava o contato direto com as duas metrópoles da Região Sul (Curitiba e Porto Alegre) e com o restante do país, a rede de rodovias estaduais exerceu um papel decisivo na configuração urbana de Santa Catarina. As principais cidades que, ao longo do litoral, localizavam-se próximas de eixos rodoviários e/ou acessos portuários adquiriram um novo dinamismo, traduzindo no território catarinense as determinações de uma lógica capitalista expressa por novas relações políticas e econômicas. A difusão do uso do automóvel voltado ao transporte de pessoas para deslocamentos de curtas e médias distâncias, 
assim como o privilegiamento do transporte de mercadorias através do sistema rodoviário provocou um crescimento contínuo na frota nacional de veículos.

Tabela 2- Municípios com Maior Proporção de Veículos por Habitante

\begin{tabular}{llll}
\hline Municípios & Proporção & Santa Catarina & Brasil \\
\hline Brusque & 0,71 & $1 \underline{a}$ & $2 \underline{a}$ \\
Blumenau & 0,64 & $2 \underline{a}$ & $9 \underline{a}$ \\
Itajaí & 0,62 & $3 \underline{a}$ & $15^{a} \underline{a}$ \\
Florianópolis & 0,61 & $4 \underline{a}$ & $16^{\underline{a}}$ \\
Chapecó & 0,61 & $5 \underline{a}$ & $19 \underline{a}$ \\
Jaraguá do Sul & 0,60 & $6 \underline{a}$ & $20 \underline{a}$ \\
Balneário Camboriú & 0,59 & $7 \underline{a}$ & $24 \underline{a}$ \\
Criciúma & 0,56 & $8^{\underline{a}}$ & $30^{\underline{a}}$ \\
Joinville & 0,53 & $9 \underline{a}$ & $45^{\underline{a}}$ \\
São José & 0,52 & $10 \underline{a}$ & $49 \underline{a}$ \\
\hline Fonte: IBGE (2010) & & &
\end{tabular}

No início da década de 1990, ultrapassada a crise dos anos 80 em que a economia do país entrou num processo recessivo, foram adotadas políticas neoliberais que afastaram o Estado brasileiro da função de fomentador do desenvolvimento. Ao adotar uma política econômica de caráter neoliberal, o Brasil perdeu a capacidade de definir e gerenciar as melhores estratégias para o seu processo de desenvolvimento sócio-econômico. A estagnação advinda do endividamento do Estado nos anos de 1980 e 1990 levou à destruição, desnacionalização e reestruturação de diversos setores da economia brasileira, fragilizando-a e deixando-a mais suscetível aos acontecimentos externos. Além disso, argumentando a falta de investimentos, a ineficiência das empresas estatais e visando a atrair investimentos externos, o governo federal colocou em marcha um amplo programa de privatizações (Programa Nacional de Desestatização). A nova política econômica contribuiu para atrair capitais externos e garantir os pagamentos da balança comercial, estratégia que se revelou perniciosa para a economia e as indústrias nacionais, já que com as taxas internas de juros elevadas (o que ainda se mantém até os dias de hoje), o país acabou atraindo, ao invés de capitais produtivos, capitais especulativos. A introdução de políticas econômicas neoliberais, adotadas pelo governo de Fernando Henrique Cardoso no início dos anos de 1990, agravou a situação das rodovias brasileiras. A dotação de recursos orçamentários para a manutenção e execução de novas obras na malha viária era dificultada pelo endividamento do Estado brasileiro que impedia a retirada de novos empréstimos para viabilizar investimentos em infra-estrutura de transportes. A precariedade do sistema rodoviário brasileiro e catarinense representou, evidentemente, prejuízos ao desenvolvimento econômico fazendo com que a responsabilidade de implantação e conservação das rodovias, até então asseguradas pelo Estado, fossem transferidas, em muitos casos, sob a forma de concessões à iniciativa privada, ficando com o governo as funções de regular e supervisionar, através da Agência Nacional de Transportes 
Terrestres (ANTT), as atividades de prestação de serviços e de exploração da infra-estrutura de transportes, exercidas por terceiros.

Apesar das dificuldades estruturais e financeiras em que se encontravam os órgãos responsáveis pelo planejamento e execução de obras rodoviárias, uma nova etapa teve lugar a partir de meados da década de 1990 quando foi concluída a pavimentação do trecho Florianópolis-Lages da BR-2825 e iniciado o processo de duplicação da BR-101, no seu trecho norte, que culminou com a inauguração do túnel do morro do Boi (entre Itapema e Balneário Camboriú), em janeiro de 2000. Além da contribuição da malha rodoviária para a integração da economia regional, as melhorias na acessibilidade, a partir da década de 1970, foram decisivas para a expansão da prática do turismo de veraneio facilitando o fluxo de turistas nacionais e estrangeiros ao litoral catarinense.

O eixo representado pela BR-101 constitui uma via de escoamento da produção local e regional $^{6}$ - fundamental para a economia da Região Sul - e, ao mesmo tempo, um corredor turístico, abrigando em suas margens uma população residente que ali se fixou em razão das dinâmicas industrial e comercial, além de veranistas e turistas que se destinam aos importantes balneários situados no litoral de Santa Catarina. Ao cortar a orla costeira a BR-101 revelou suas belezas até então pouco conhecidas proporcionando o crescimento de várias cidades, tais como Tijucas, Biguaçu, São José e Palhoça e outras localidades (colônias de pescadores) até então isoladas com uma população bastante reduzida. As diversas rodovias estaduais que desembocam na BR-101, conforme pode ser visualizado no mapa 1 , constituem vias de acesso às praias, bem como de escoamento da produção de diferentes regiões do estado até os seus principais portos (Itapoá, São Francisco do Sul, Navegantes, Itajaí, Imbituba e Laguna), cujas atividades estão voltadas ao comércio de importação e exportação. Nesse mesmo mapa estão representados também os mais movimentados aeroportos catarinenses (Florianópolis, Navegantes e Joinville), localizados no litoral.

5 A rodovia BR-282 possui 670 quilômetros de extensão e liga o extremo oeste ao litoral de Santa Catarina. É a principal e mais extensa via no sentido leste-oeste, promovendo a integração da capital com as demais regiões do estado, em especial as regiões Serrana e Oeste. Parte de Florianópolis e atinge a fronteira com a Argentina, permitindo não apenas a chegada de turistas e veranistas procedentes de países vizinhos e do interior do estado (planalto, meio-oeste e extremo-oeste) às praias, mas também o escoamento da maior produção de aves e suínos do mundo, além de atender a uma elevada demanda de circulação da população local, interligando os municípios do oeste catarinense diretamente à capital. (BARBOSA, 2013, p. 16 e 19).

6 O trecho da BR 101 que vai de Palhoça até o limite norte de Santa Catarina com o Paraná está totalmente duplicado. De Palhoça para o sul a duplicação está praticamente concluída. Com a recente inauguração da Ponte Anita Garibaldi, situada em Laguna, e da abertura do Túnel do Formigão, em Tubarão, resta apenas um nó de estrangulamento do tráfego representado pela ponte do rio Tubarão, no município de Tubarão. Embora não represente propriamente um gargalo, a construção do túnel do Morro dos Cavalos, em Palhoça, foi contornada provisoriamente por uma medida paliativa representada pela abertura da quarta pista. Além das Rodovias Federais BR 470, BR 282 e a BR 280, que chega ao porto de São Francisco do Sul, merecem destaque as Rodovias Estaduais, dentre as quais a SC 470, que segue pela margem direita do Rio Itajaí-Açu até o porto de Itajaí. Há também outra importante rodovia estadual, a atual SC 418 (ex-301), também chamada de Dona Francisca. O fluxo dessas rodovias converge para o litoral catarinense desembocando na BR-101 ou levando mercadorias aos portos. 
Mapa 1 - Litoral Catarinense

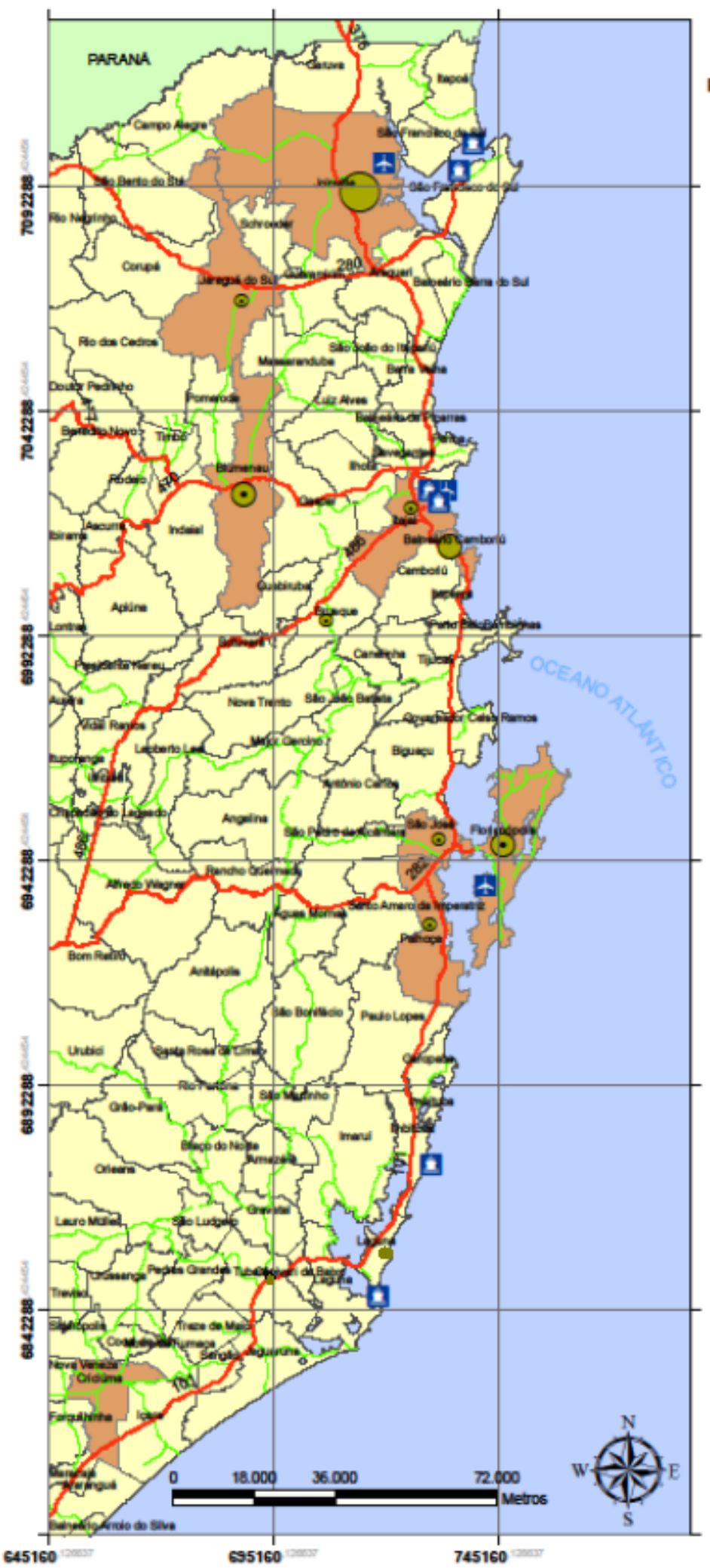

Mapa de Santa Catarina com a divisão em municipios e o traçado das principais rodovias estaduais e federais, e as cidades mais populosas.

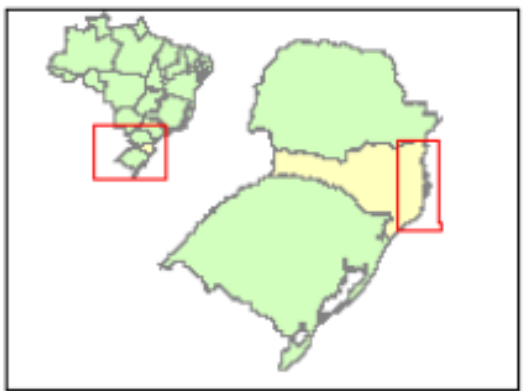

\section{Legenda}

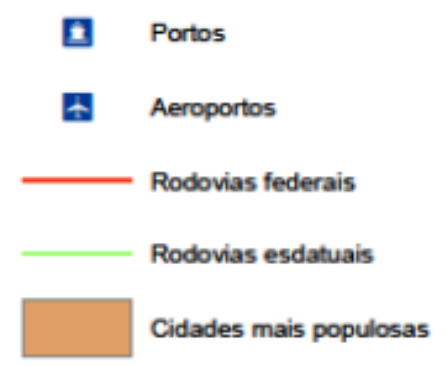

Número de shopping centers:

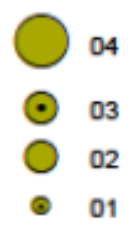

Dados Cartborticos

Exaoraso por:

Geovan Martins Guimarles

Font:
Dados cedidos peto Empreendedor

Mapoleca Digtai ERMGAI-CIRAM BeE 150000

DEN NFA - Departamento Estadua de intoestrahn DNIT-Depatamento Nacional de intaeth tura de Transportes
astema de Frojeçlo UTM

645160

Além da contribuição da malha rodoviária para integração regional, é preciso destacar o impulso que a abertura da BR-101 representou para toda a fachada atlântica catarinense, que se 
tornou alvo de investimentos voltados para vários setores da economia. Enquanto via de escoamento da produção, ela estimulou o desenvolvimento regional que redundou na concentração de indústrias, empresas prestadoras de serviços e de suporte a grandes grupos, como é o caso dos centros de distribuição de supermercados (Centro de Distribuição dos Supermercados Imperatriz, em Palhoça e Centro de Distribuição do Angeloni, em Porto Belo) e de centros de distribuição de cadeias de lojas, como é o caso do Centro de Distribuição Litoral das Lojas Berlanda, que possui 48 lojas em todo o estado, situado no município de Porto Belo. 0 processo de urbanização que induziu a conurbação dos aglomerados urbanos, sobretudo ao longo do trecho centro-norte da BR-101, transformou-a numa rodovia intermunicipal em que caminhões e veículos de passageiros que por ela circulam estão em constante disputa. O aumento da densidade demográfica, somado aos elevados índices de desenvolvimento humano da população ${ }^{7}$ ao expressivo PIB dos municípios $\operatorname{costeiros}^{8}$, conforme pode ser observado no gráfico 2, acabou atraindo atividades comerciais para esse eixo, como é o caso da Havan, que possui 19 lojas localizadas entre os municípios de Palhoça e Joinville. Outro dado que merece destaque diz respeito à multiplicação dos Shoppings Centers nessa mesma área geográfica (2 em Balneário Camboriú, 3 em Blumenau, 1 em Brusque, 3 em Florianópolis, 1 em Itajaí, 1 em Jaraguá do Sul, 3 em Joinville, 1 em Palhoça, 2 em São José, 1 em Criciúma e 1 em Tubarão) ${ }^{9}$. Tal realidade permite constatar, apesar dos limites desse artigo, o surpreendente crescimento do comércio varejista, o que leva ao reconhecimento do peso das atividades de serviço nos espaços econômicos mais dinâmicos de Santa Catarina. Por outro lado, cumpre considerar que o processo de concentração, somado à modernização tornou-se, a partir do início dos anos de 1990, uma nítida estratégia de sobrevivência frente ao avanço das idéias neoliberais que favorecem a entrada de redes internacionais.

7 Santa Catarina é um dos estados brasileiros com melhor qualidade de vida, e vem evoluindo ano a ano em diversos indicadores sociais. O Estado tem o menor índice de desigualdade (índice GINI) com 0,445(medida do grau de concentração do rendimento). O Brasil tem índice 0,508 (IBGE -PNAD - Pesquisa Nacional por Amostra de Domicílios 2011); Santa Catarina também apresenta a menor taxa de mortalidade infantil (9,2 por 1.000 nascimentos vivos - IBGE- Instituto Brasileiro de Geografia e Estatística e tem a maior expectativa de vida (76,8 anos), segundo o IBGE.

8 A tendência é o município de Itajaí passar a ser o primeiro de Santa Catarina em Produto Interno Bruto (PIB), superando Joinville, graças ao dinamismo do seu porto, ao polo de saúde ali instalado (18 empresas), de quatro estaleiros, da infra-estrutura de armazenagem e alfandegamento ( 2 milhões de metros quadrados de área) e da sede da BR-Foods e Marfrig."

9 Conforme busca em sites, dos 19 shoppings localizados nas cidades apontadas, seis (Continente Shopping, Garten Shopping, Balneário Shopping, Neumarkt Shopping, Norte Shopping e Nações Shopping) pertencem ao Grupo Almeida Junior, fundado em Blumenau em 1980, que entrou no setor de shopping centers em 1990 e a partir de 2008 decidiu estrategicamente concentrar suas atividades em Santa Catarina. Atualmente é considerada a maior empresa regional de Shopping Centers do Brasil. Apenas um dos shoppings situados nas cidades litorâneas de Santa Catarina, o Shopping Iguatemi de Florianópolis, pertence à rede Iguatemi - Empresa de Shopping Centers S. A. -, fundada em 1979 como uma sociedade anônima, tornando-se, em 1983, uma empresa do Grupo Jereissati que atua no setor de shoppings centers no Brasil. 
Gráfico 1- Municípios catarinenses com maiores valores de PIB, em 2010 (R\$ milhões)

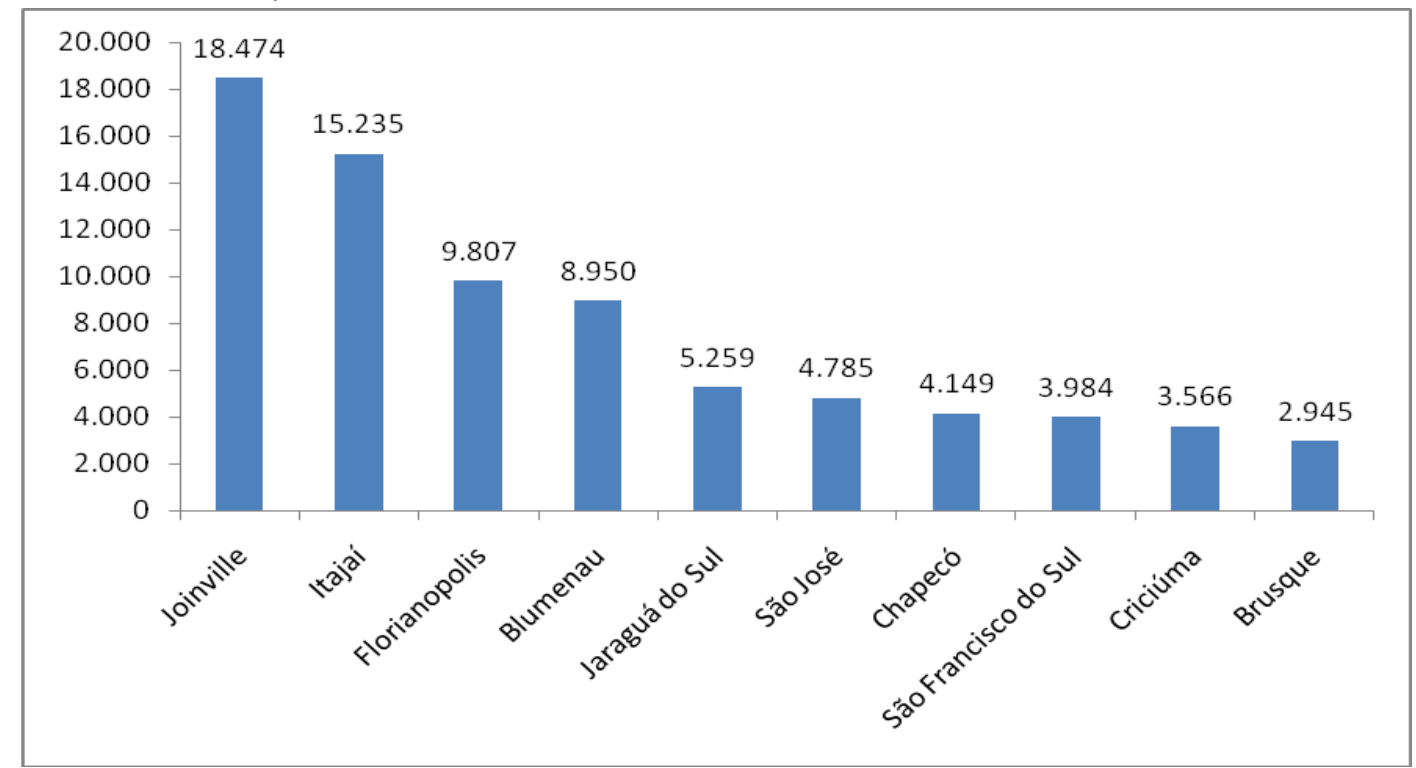

Fonte: IBGE

Por seus diversos atrativos paisagísticos e culturais, o turismo representa uma importante fonte de renda no contexto econômico do estado e, em particular, de diversos municípios do litoral catarinense. Como uma atividade ligada essencialmente ao consumo e, portanto, intrínseca ao capitalismo, é evidente que esse processo extrapolou a esfera do lazer e do descanso iniciado com a construção das "segundas residências" que se multiplicaram pelos balneários do estado. 0 aumento da procura por imóveis situados à beira-mar, fruto do marketing do lugar, transformou as propriedades em fonte de renda ou em investimento (Danielski, 2009), dando origem a grandes construtoras e empreendimentos imobiliários que promoveram um acelerado processo de verticalização dos centros urbanos e de diversos balneários catarinenses. Com a chegada do novo milênio, conforme Campos (2010, p. 29), ocorreu uma verdadeira "explosão imobiliária" que impulsionou de forma definitiva o crescimento e a expansão urbana não apenas de Florianópolis, como de todo o litoral. Convém lembrar ainda que o mercado turístico corresponde a um conjunto de atividades e serviços referentes à interação da demanda e oferta de produtos relacionados à produção de bens e de serviços ao turista que, como qualquer negócio da sociedade capitalista, visa ao lucro e à rentabilidade. No caso do setor hoteleiro de Santa Catarina, o capitalismo engendrado nas áreas de pequena produção mercantil é que deu origem aos primeiros empreendimentos, inicialmente modestos, aproveitando as oportunidades lucrativas que iam surgindo na medida em que as várias regiões se desenvolviam. Segundo recente pesquisa realizada por Santos (2012), o setor hoteleiro catarinense é bastante diversificado e vêm buscando se adaptar às especificidades de cada região. Predominam os hotéis independentes (93\%), com administração predominantemente familiar, ou seja, não estão vinculados a redes hoteleiras internacionais, nacionais e/ou regionais. O universo de estabelecimentos administrados por redes hoteleiras representa apenas $7 \%$, sendo que desses $44 \%$ pertencem a uma única rede - a Accor -, $50 \%$ a redes nacionais e apenas $6 \%$ são de redes regionais. 


\section{CONSIDERAÇÕES FINAIS}

Como se pode constatar, os dados apresentados comprovam que a organização dos espaços localizados na fachada atlântica de Santa Catarina é marcada por disputas inerentes ao desenvolvimento de múltiplas iniciativas, nascidas num ambiente de extrema concorrência, cuja raiz deriva do extraordinário desempenho capitalista dessa singular formação sócioespacial. O processo de industrialização do país alavancado a partir da Revolução de 1930 favoreceu o desenvolvimento industrial dos núcleos de colonização catarinenses cujo dinamismo se estendeu, lentamente a partir de meados do século passado, em razão de uma nova conjuntura, às áreas litorâneas até então mais atrasadas. Por outro lado, buscou-se demonstrar que o dinamismo socioeconômico e a reorganização espacial apresentados pelo litoral catarinense nas últimas décadas podem ser interpretados como uma reação à conjuntura depressiva da economia mundial e nacional que levou a um forte processo de concentração de empresas como forma de ganhar competitividade e de assegurar sua sobrevivência através da adoção de medidas e práticas, tais como a minimização dos custos através da incorporação de técnicas e processos inovadores, flexibilização das relações de trabaIho e proximidade de rodovias e portos. As mudanças estão, pois, diretamente relacionadas ao novo contexto marcado pelo neoliberalismo, nas três últimas décadas.

Cumpre destacar ainda que os atrativos paisagísticos e culturais de Santa Catarina, e em particular do seu litoral, estimularam o crescimento dos fluxos turísticos extrapolando a esfera do lazer e do descanso iniciado com a construção de "segundas" residências de veranistas, promovendo o desenvolvimento de um conjunto de atividades e serviços para atender a demanda que impulsionaram a expansão urbana nos municípios situados no litoral de Santa Catarina.

As reflexões apresentadas ao longo do artigo demonstram a pertinência e a validade do referencial teórico utilizado na análise do dinamismo sócio- espacial do litoral catarinense, que resulta da relação dialética entre elementos naturais e humanos característicos dessa região, bem como da combinação de determinações locais, regionais, nacionais e mundiais em diferentes etapas da formação brasileira.

\section{REFERÊNCIAS}

Barbosa, A.M. P. (2013). Rodoviarismo e Integração: a ideologia e a política da modernização conservadora catarinense. Dissertação (Mestrado em Geografia) - Centro de Filosofia e Ciências Humanas, UFSC, Florianópolis.

Campos, E.T. (2010). A expansão urbana na região metropolitana de Florianópolis. Florianópolis: Insular.

Cholley, A. (1964). Observações sobre alguns pontos de vista geográficos. In: Boletim Geográfico. Rio de Janeiro: CNG, n.179 e 180.

Danielski, M. (2009). Padrão Arquitetônico e Representação Social na Paisagem da Beira-Mar de Balneário Camboriú/SC. 275 f. Dissertação (Mestrado em Geografia) - Centro de Filosofia e Ciências Humanas, UFSC, Florianópolis.

IBGE - INSTITUTO BRASILEIRO DE GEOGRAFIA E ESTATÍSTICA. Contagem Populacional. Disponível em:<http://www.sidra.ibge.gov.br/bda/popul/d...>Acesso em: jan. 2014. 
IBPT - INSTITUTO BRASILEIRO DE PLANEJAMENTO TRIBUTÁRIO. Estudo sobre arrecadação de IPVA e sua proporcionalidade em relação à frota de veículos e à população brasileira. 2011. Disponível em: <https://www.ibpt.org.br> Acesso em: set. 2013.

Fundação Cultural Balneário Camboriú. (jun. 2009). Informativo MEMPI: Memória - Patrimônio - Informação. Ano 04 Ed. 5. Balneário Camboriú: Arquivo Histórico de Balneário Camboriú.

Mamigonian, A. (1966). Estudo geográfico das indústrias de Blumenau. In: Separata da Revista Brasileira de Geografia, $\mathrm{n}^{\circ} 3$, Rio de Janeiro.

. (1966). Vida Regional em Santa Catarina. In: Revista Orientação. IG-USP, n.2.

(1986). Indústria. In: Atlas de Santa Catarina. Florianópolis: GAPLAN.

(2000). Teorias sobre a Industrialização brasileira. Cadernos Geográficos. Florianópolis: UFSC/

$\mathrm{CFH}$.

(2009). O Nordeste e o Sudeste na Divisão Regional do Brasil. In: Geografia Econômica - Anais de Geografia Econômica e Social. Florianópolis: UFSC/Departamento de Geociências, jan.

Peluso Jr., V. A. (1991). Aspectos geográficos de Santa Catarina. Florianópolis: FCC/EDUFSC. (1952). O Relevo do Estado de Santa Catarina. Florianópolis: CNG/DEGC.

Pereira, R. M. F. A. (2003). Formação sócioespacial do litoral de Santa Catarina (Brasil): gênese e transformações recentes. Geosul (UFSC), Florianópolis - SC, v. 18, n. 35, p. 99-129.

- (2011). Santa Catarina no contexto da formação sócioespacial do Brasil Meridional: do período colonial ao início do século XX. In: Mamigonian, A. (Org). Santa Catarina: Estudos de geografia econômica e social. Florianópolis: GCN/CFH/UFSC, p. 13-30.

. (dez. 2013). Sistema Rodoviário e Turismo no Litoral do Estado de Santa Catarina - Brasil. TURyDES. Málaga, v. 6, p. 1-14.

. (mai-ago. 2015) Origens, Evolução e tendências do Setor Hoteleiro de Balneário Camboriú. Revista Turismo - Visão e Ação, Balneário Camboriú, v. 17, n. 2, p. 508 -537.

Rangel, I.M. (2005). Obras Reunidas (vol. 1 e 2). Rio de Janeiro: Contraponto.

Santos, F. M. (2012). Geografia das Redes Hoteleiras: mundo, Brasil e Santa Catarina. 397f. Tese (Doutorado em Geografia). Universidade Federal de Santa Catarina, Florianópolis.

Santos,M. (1982). Espaço e Sociedade. Petrópolis: Vozes. (2014). Espaço e Método. 5.ed. São Paulo. Edusp (Coleção Milton Santos) 